\title{
Knowledge, Attitude and Practice Towards Vaccination among Parents in Al Qassim Region, Saudi Arabia
}

\author{
Mohammad A Alhasoon ${ }^{1 *}$, Renad alkhalifah ${ }^{2}$, Renad Alazzam² , Ashwag Almoteri² ${ }^{2}$ Ryman alrayes ${ }^{2}$ Fay almutairi $^{2}$ \\ and Alaa alkhaliwi ${ }^{2}$ \\ ${ }^{1}$ Pediatric Department, Qassim University, Saudi Arabia \\ ${ }^{2}$ Medical Student, Qassim University, Saudi Arabia \\ Submission: February 27, 2020 Published: March 11, 2020 \\ *Corresponding author: Mohammad A Alhasoon, Assistant Professor, Pediatric Department, Unaizah College of Medicine, Qassim University, Saudi \\ Arabia
}

\section{Abstract}

Introduction: Immunization is the most effective health intervention which reduces hospitalization, morbidity and mortality. It's become the vital part in public health and plays the major role in disease prevention but remains a controversial topic in our society. It has been recently reported by WHO that a large proportion of children fail to complete their immunization schedule.

Aim: This study aimed to assess knowledge, attitude, and practice of parents towards vaccination and compare findings with demographic characteristics of the studied group.

Materials and methods: This is a cross-sectional study to parents who work in Qassim schools (Buraydah, Unayzah, Al-Methnab, Al-Rass, Riyadh Al-Khabra, Al-badayea) and also distributed among health centers in villages and cities as well as hospitals. Validated questionnaire consisted of three sections that collected information on parents' demographics, awareness, knowledge of vaccine benefits and practices regarding the immunization of their children were distributed among targeted parents. The questionnaire had brief explanation of the idea of the research to children parents. Data was collected through online and paper questionnaire, Responses to knowledge questions were recorded as "Yes", “No", “I don't know", “disagree”, “agree” and "neutral." All data analyses were carried using SPSS version 21.

Results: The overall mean knowledge score was $6.29 \pm 1.95$ out of 10 and moderate, good and poor knowledge were found to $66.9 \%, 26.6 \%$ and $6.5 \%$ of parents respectively. With regards to attitude, the overall mean attitude score was $19.2 \pm 1.67$ out of 21 and nearly all parents had positive attitude $(82.7 \%)$ followed by average $(16.1 \%)$ and negative attitude $(1.2 \%)$. With regards to practice, the overall practice score was $20.9 \pm 2.28$ out of 24 and good, moderate and poor attitude were observed to $60.9 \%, 36.7 \%$ and $2.4 \%$ of the parents respectively. Furthermore, Child unable to complete vaccinations was identified as the significant factor of knowledge ( $T=-2.861, \mathrm{p}-0.004)$, attitude $(\mathrm{t}=-3.469, \mathrm{p}-0.007)$ and practice score $(\mathrm{T}=-3.642, \mathrm{p}-<0.001)$.

Conclusion: There is a moderate knowledge among parents toward childhood immunization while the consensus to attitude and practice deemed positive and good. Furthermore, unable to complete child vaccination was the significant predictor of knowledge, attitude and practice toward childhood vaccination.

Keywords: Vaccination; Knowledge; Attitude; Practice; Parents; Childhood

\section{Statistical Analysis Method}

Descriptive statistics had been presented using counts, proportions (\%), mean \pm standard deviation whenever appropriate. The comparison between the knowledge, attitude and practices (KAP) score had been conducted using Chi Square test. A correlation procedure of knowledge, attitude and practice sore were also conducted to determine the linear relationship of each KAP score. A p-value cut off point of 0.05 at $95 \%$ CI used to determine statistical significance. Statistical collinearity was measured using Shapiro Wilk test. All data analyses were performed using the statistical package for social sciences, version 21 (SPSS, Chicago, IL, USA) [1]. The evaluation of parents' knowledge toward child vaccination which comprised of 10 question has been described at table 1 where the correct answer for each question has been presented and coded as 1 . The total 
knowledge score has been calculated by adding the 10 questions and an overall score range from 0 to 10 has been generated. Parents were classified as having low knowledge by the score range of $0-3$, moderate knowledge by the score range of 4-7 and high knowledge by the score range of 8-10. The assessment of parents' attitude toward child vaccination which composed of 7 questions has been elaborated at table 2 where "disagree" coded as 1, "neutral" coded as 2 and "agree" coded as 3 were the answer options [2]. The total attitude score has been calculated by summing up the 7 questions and total score range from 9-21 has been generated. Parents were classified as having negative attitude by the score range of 9-13, average attitude by the score range of 14-18 and positive attitude by the score range of 19-21. The measurement of parents' practice toward child vaccination which consisted of 8 question has been determined at table 3 where "disagree" coded as 1 , "neutral" coded as 2 and "agree" coded as 3 were the answer options. The total practice score has been computed by adding up the 8 questions and a total score range from 12-24 has been generated. Parents were classified as having low practice by the score range of 12 to 15 , moderate practice by the score range of 16-20 and high practice by the score range of 21-24 [3].

Table 1: Determinants of parents' knowledge toward child vaccination ${ }^{(n=417)}$.

\begin{tabular}{|c|c|}
\hline Knowledge Statement & Correct Answer N (\%) \\
\hline Mandatory vaccinations protect children from infectious diseases & $360(86.3 \%)$ \\
\hline The first vaccine is given at birth & $384(92.1 \%)$ \\
\hline Most diseases vaccinated against occur in the first year of life & $173(41.5 \%)$ \\
\hline Multiple doses of the same vaccine are given at period that are important in child & $296(71.0 \%)$ \\
\hline Vaccination with more than one vaccine at the same time has no side effects on child & $152(36.5 \%)$ \\
\hline It's important to vaccinate during vaccination campaigns & $317(76.0 \%)$ \\
\hline Its recommended to vaccinate against seasonal flu & $184(44.1 \%)$ \\
\hline Vaccination can cause Autism & $232(55.6 \%)$ \\
\hline Flu, ear infections and diarrhea are not contraindications of vaccination & $137(32.9 \%)$ \\
\hline Some vaccines have side effects like Fever & $392(94.0 \%)$ \\
\hline
\end{tabular}

Table 2: Determinants of parents' attitude toward child vaccination ${ }^{(\mathrm{n}=417)}$.

\begin{tabular}{|c|c|c|c|}
\hline Attitude Statement & Disagree N (\%) & Neutral N (\%) & Agree N (\%) \\
\hline Vaccinations are important for protecting children & $05(01.2 \%)$ & $34(08.2 \%)$ & $378(90.6 \%)$ \\
\hline Vaccinations have more benefits than harms & $09(02.2 \%)$ & $43(10.3 \%)$ & $365(87.5 \%)$ \\
\hline Vaccinations are safe for children & $03(0.70 \%)$ & $51(12.2 \%)$ & $363(87.1 \%)$ \\
\hline Religion forbid vaccination & $386(92.6 \%)$ & $24(05.8 \%)$ & $07(01.7 \%)$ \\
\hline Children can get the diseases they're vaccinated against & $168(40.3 \%)$ & $129(30.9 \%)$ & $120(28.8 \%)$ \\
\hline Following the mandatory vaccination schedule & $09(02.2 \%)$ & $24(05.8 \%)$ & $384(92.1 \%)$ \\
\hline Vaccinations preserve children's health & $08(01.9 \%)$ & $37(08.9 \%)$ & $372(89.2 \%)$ \\
\hline
\end{tabular}

Table 3: Determinants of parents' practice toward child vaccination ${ }^{(n=417)}$.

\begin{tabular}{|c|c|c|c|}
\hline Practice Statement & Disagree N (\%) & Neutral N (\%) & Agree N (\%) \\
\hline Advice/counseling is given by doctors & $27(06.5 \%)$ & $51(12.2 \%)$ & $339(81.3 \%)$ \\
\hline Vaccination was done on correct dates & $13(03.1 \%)$ & $41(09.8 \%)$ & $363(87.1 \%)$ \\
\hline Getting information from HCP about the side effects & $35(08.4 \%)$ & $53(12.7 \%)$ & $329(78.9 \%)$ \\
\hline Children had side effects after being vaccinated & $154(36.9 \%)$ & $99(23.7 \%)$ & $164(39.3 \%)$ \\
\hline Continue vaccinating after having side effects & $117(28.1 \%)$ & $112(26.9 \%)$ & $188(45.1 \%)$ \\
\hline All children completed their vaccinations & $29(07.0 \%)$ & $23(05.5 \%)$ & $365(87.5 \%)$ \\
\hline Intending to vaccinate the new child & $10(02.4 \%)$ & $16(03.8 \%)$ & $391(93.8 \%)$ \\
\hline Completely satisfied about vaccination in Saudi Arabia & $26(06.2 \%)$ & $45(10.8 \%)$ & $346(83.0 \%)$ \\
\hline
\end{tabular}

HCP: Healthcare Provider.

\section{Results}

The majority of the surveyed mothers (79.4\%) were between $31-40$ years old $(52.0 \%)$ with nearly all were Saudis $(97.8 \%)$ and living in Urban (89\%). With regards to parents' education, a high proportion of fathers and mothers had bachelor or higher degree with $65.9 \%$ and $76.3 \%$ respectively. Of them, a relatively fewer were working at medical field $(4.8 \%)$ with more than a half had more than three children (58.5\%). Additionally, there were 
$44.6 \%$ of them were having a child under school age while many of the parents stated that their child was able to finish complete vaccinations (69.8\%) (Table 4 \& Figure 1).

Figure 1 presented the distribution of residence city of parents. Majority of them were living in Alrass (35.5\%), followed by Al-badaya (14.1\%) and Almethnab (14.1\%) while the least of them were living at Albukayriyah (Table 1). The details of the determinants of parents' knowledge toward child vaccination has been elaborated at table 1 . Based on the results, nearly all of them $(86.3 \%)$ believe that mandatory vaccinations protect children from infectious diseases and most of them believe that first vaccine should be given at birth (92.1\%) [4]. However, majority of them were unaware that most diseases occur in the first year of life $(41.5 \%)$ while their knowledge was high with regards to the statement about "multiple doses of the same vaccine are given at period that are important in child" (71.0\%). Furthermore, their knowledge was low with regards to the statement about "vaccination with more than one vaccine at the same time has no side effects on child immunization" (36.5\%) while most of them believe that it is important to vaccinate during vaccination campaigns (76.0\%). A low knowledge was also determined with regards to the recommendation to vaccinate against seasonal flu $(44.1 \%)$ while their knowledge was moderate with regards to the statement about "vaccination can cause autism" (55.6\%). In contrast, their knowledge was poor with regards to the statement about "Flu, ear infections and diarrhea are not contraindication of vaccination" (32.9\%) whereas nearly all of them believe that some vaccines have side effects like fever (94\%) (Table 2). In the determinants of parents' attitude toward child vaccination, it was revealed that among the 7 determinants of attitude, most of them agreed on the following statement such as "Vaccinations are important for protecting children" (90.6\%), "Vaccinations have more benefits than harms" (87.5\%), "Following the mandatory vaccination schedule" (92.1\%) and "Vaccinations preserve children's health" (89.2\%) [5]. On the other hand, most of them disagreed with regards to the statement about "Religion forbid vaccination" (92.6\%) while majority of the parents also disagreed in the statement about "Children can get the diseases they're vaccination against" (40.3\%) (Table 3 ). In the determinants of parents' practice toward child vaccination, we found that among 8 statements that determined their practice, nearly all of them agreed on the following statements such as; "Advice/counseling is given by doctors" (81.3\%), "Vaccination was done on correct dates" (87.1\%), "Getting information from healthcare provider about the side effects of vaccination" (78.9\%), "All children completed their vaccinations" (87.5\%), "Intending to vaccinate the new child" (93.8\%) and "Completely satisfied about vaccination in Saudi Arabia" (83\%). On the other hand, parents had poor practices on the following statement such as; "Children had side effects after being vaccinated" (39.3\%) and "Continue vaccinating after having side effects" (45.1\%) (Table 5). Table 5 showed the prevalence of parents' knowledge, attitude and practice toward childhood vaccination. Based on the results, the overall mean knowledge score was $6.29 \pm 1.95$ out of 10 and the level of knowledge showed, $26.6 \%$ of the parents had good knowledge, $66.9 \%$ of moderate knowledge and $6.5 \%$ of poor knowledge. With regards to attitude, the overall mean attitude score was $19.2 \pm 1.67$ out of 21 and the level of attitude showed, $82.7 \%$ of the parents were classified as having positive attitude, $16.1 \%$ found to have average attitude and $1.2 \%$ found to have negative attitude. With regards to practice, the overall mean practice score was $20.9 \pm 2.28$ out of 24 and the level of practice showed, $60.9 \%$ were identified as having good practices, $36.7 \%$ of moderate practice and $2.4 \%$ of poor practice (Figure 2).

Table 4: Socio demographic characteristics of parents $\mathrm{s}^{(\mathrm{n}=417)}$.

\begin{tabular}{|c|c|}
\hline Study Variables & N (\%) \\
\hline \multicolumn{2}{|l|}{ Age Group } \\
\hline $20-30$ years & $56(13.4 \%)$ \\
\hline $31-40$ years & $217(52.0 \%)$ \\
\hline$>40$ years & $144(34.5 \%)$ \\
\hline \multicolumn{2}{|l|}{ Gender } \\
\hline Mother & $331(79.4 \%)$ \\
\hline Father & $86(20.6 \%)$ \\
\hline \multicolumn{2}{|l|}{ Nationality } \\
\hline Saudi & $408(97.8 \%)$ \\
\hline Non-Saudi & $09(02.2 \%)$ \\
\hline \multicolumn{2}{|l|}{ Residence Place } \\
\hline Urban & $371(89.0 \%)$ \\
\hline Rural & $46(11.0 \%)$ \\
\hline \multicolumn{2}{|l|}{ Father Educational Level } \\
\hline High school or below & $142(34.1 \%)$ \\
\hline Bachelor or higher & $275(65.9 \%)$ \\
\hline \multicolumn{2}{|l|}{ Mother Educational Level } \\
\hline High school or below & $99(23.7 \%)$ \\
\hline Bachelor or higher & $318(76.3 \%)$ \\
\hline \multicolumn{2}{|l|}{ Working in Medical Field } \\
\hline Yes & $20(04.8 \%)$ \\
\hline No & $397(95.2 \%)$ \\
\hline \multicolumn{2}{|l|}{ Number of Children } \\
\hline One & $58(13.9 \%)$ \\
\hline Two to three & $115(27.6 \%)$ \\
\hline More than three & $244(58.5 \%)$ \\
\hline \multicolumn{2}{|l|}{ Having Children Under School Age } \\
\hline Yes & $186(44.6 \%)$ \\
\hline No & $231(55.4 \%)$ \\
\hline \multicolumn{2}{|l|}{$\begin{array}{l}\text { Number of Children Who Were Unable to Complete } \\
\text { Vaccinations }\end{array}$} \\
\hline None & $291(69.8 \%)$ \\
\hline One & $101(24.2 \%)$ \\
\hline Two to three & $25(06.0 \%)$ \\
\hline
\end{tabular}




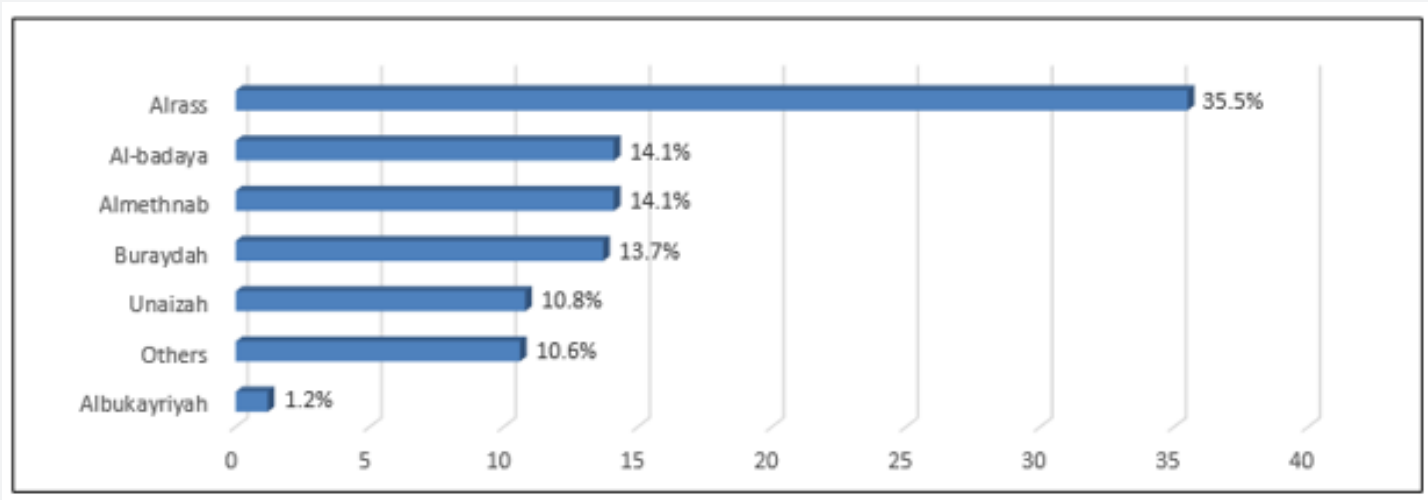

Figure 1: Distribution of residence city of parents.

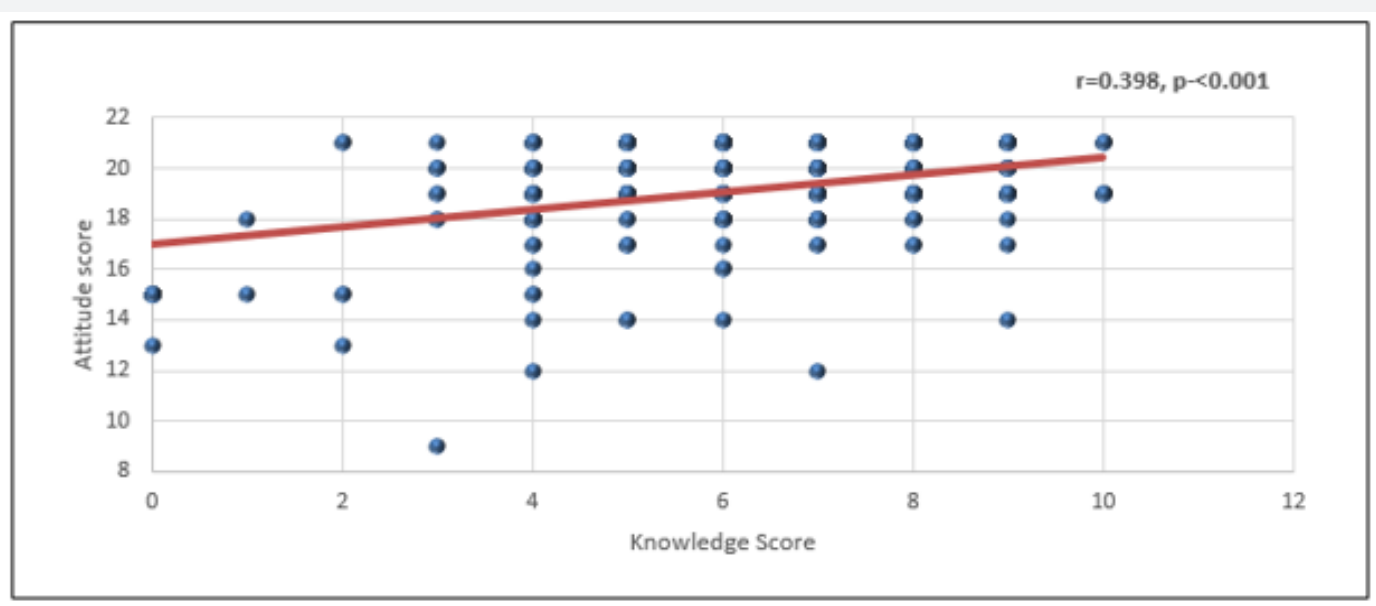

Figure 2: Correlation (Pearson-R) between knowledge and attitude score.

Table 5: Prevalence of parents' knowledge, attitude and practice toward child vaccination $^{(n=417)}$.

\begin{tabular}{|c|c|}
\hline \multicolumn{2}{|c|}{ Level of knowledge } \\
\hline Poor & $27(06.5 \%)$ \\
\hline Moderate & $279(66.9 \%)$ \\
\hline Good & $111(26.6 \%)$ \\
\hline Attitude Score (mean \pm SD) & $19.2 \pm 1.67$ \\
\hline \multicolumn{2}{|c|}{ Level of attitude } \\
\hline Negative & $05(01.2 \%)$ \\
\hline Average & $67(16.1 \%)$ \\
\hline Positive & $345(82.7 \%)$ \\
\hline Practice score (mean \pm SD) & $20.9 \pm 2.28$ \\
\hline \multicolumn{2}{|c|}{ Level of practice } \\
\hline Moderate & $10(02.4 \%)$ \\
\hline Good & $254(60.9 \%)$ \\
\hline
\end{tabular}

A Pearson correlation has been conducted at figure 2 to determine the linear relationship between knowledge and attitude score. It was found that a highly positive correlation was detected between knowledge and attitude score $(\mathrm{r}=0.398, \mathrm{p}-<0.001)$ suggesting that while the knowledge is increased the attitude also will likely increase (Figure 3). In Figure 3, the correlation was statistically highly significant between knowledge and practice score $(\mathrm{r}=0.442, \mathrm{p}-<0.001)$, suggesting that while the knowledge is increased the practice will also increase (Figure 4). In figure 4 , it was found that a positive significant correlation has been observed between attitude and practice score which indicates that an increase of parents' attitude will also signifies an increase of practice (Table 6). When comparing the knowledge, attitude and practice score among the socio demographic characteristics of parents, we found that, those parents with having two to three children are significantly less of having knowledge score ( $F=3.619, p-0.041)$ while attitude and practice score did not differ significantly among the number of children. Those parents with having children under school age are significantly less of having knowledge score ( $\mathrm{T}=-3.003, \mathrm{p}-0.016)$ and practice score $(\mathrm{T}=-$ 1.913, p-0.032) but no difference found on attitude score [6]. We also observed that those parents who were able to complete vaccinations schedule have significantly more of having knowledge score ( $\mathrm{T}=-2.861, \mathrm{p}-0.004)$, attitude score ( $\mathrm{T}=-3.469, \mathrm{p}-0.007)$ and practice score $(\mathrm{T}=-3.642, \mathrm{p}-<0.001)$. On the other hand, age group, 
gender, nationality, city, residence place, father educational level, differ significantly among the knowledge, attitude and practice mother educational level and working in medical field did not score (Table 6).

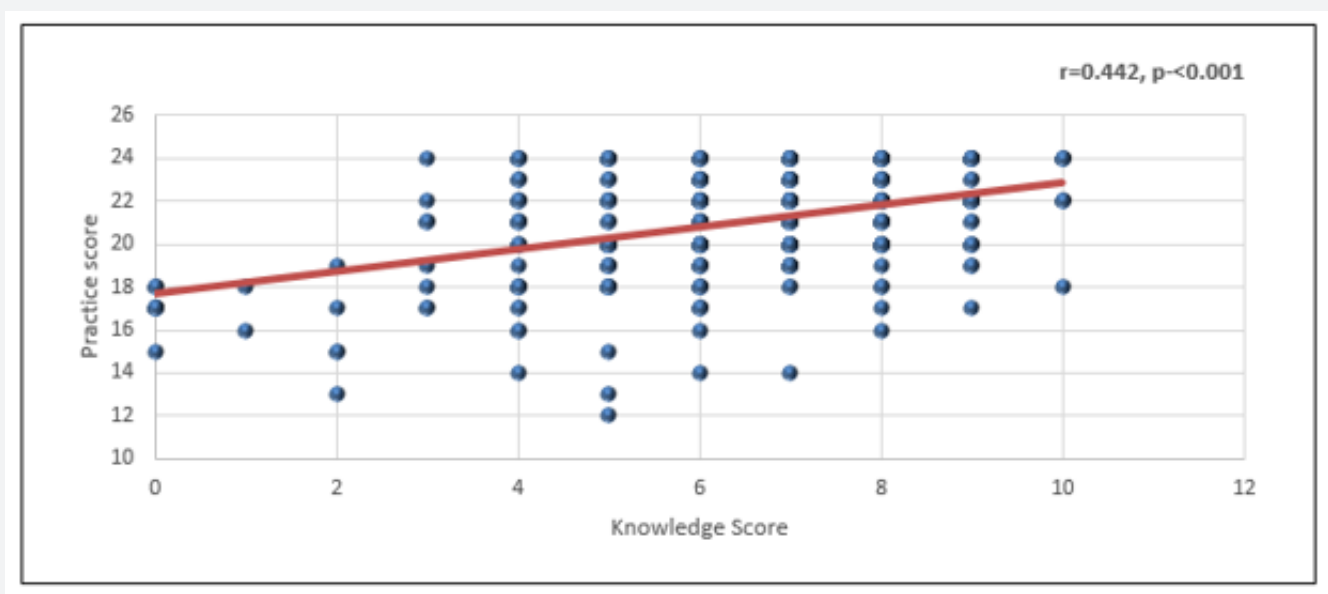

Figure 3: Correlation (Pearson-R) between knowledge and practice score.

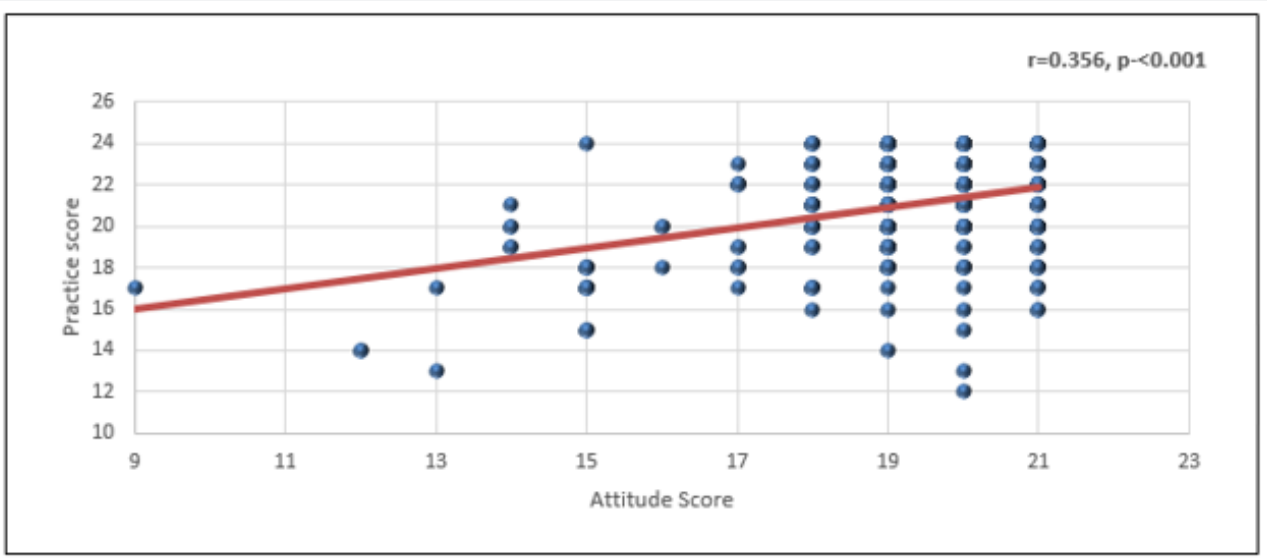

Figure 4: Correlation (Pearson-R) between attitude and practice score.

Table 6: Comparison of knowledge, attitude and practices score among the socio demographic characteristics of parents ${ }^{(n=417)}$.

\begin{tabular}{|c|c|c|c|}
\hline Factor & $\begin{array}{c}\text { Knowledge } \\
\text { Total Score (10) } \\
\text { (mean } \pm \text { SD) }\end{array}$ & $\begin{array}{c}\text { Attitude Score } \\
\text { Total Score (21) } \\
\text { (mean } \pm \text { SD) }\end{array}$ & $\begin{array}{c}\text { Practice } \\
\text { Total Score (24) } \\
\text { (mean } \pm \text { SD) }\end{array}$ \\
\hline \multicolumn{4}{|c|}{ Age group ${ }^{a}$} \\
\hline $20-30$ years & $6.45 \pm 1.99$ & $19.4 \pm 1.31$ & $21.0 \pm 2.17$ \\
\hline $31-40$ years & $6.25 \pm 1.98$ & $19.0 \pm 1.75$ & $20.9 \pm 2.22$ \\
\hline$>40$ years & $6.31 \pm 1.88$ & $19.3 \pm 1.64$ & $21.0 \pm 2.41$ \\
\hline $\mathrm{F}=$ Test; P-value & $\mathrm{F}=0.223 ; 0.622$ & $\mathrm{~F}=2.008 ; 0.069$ & $\mathrm{~F}=0.102 ; 0.662$ \\
\hline \multicolumn{4}{|c|}{ Gender $^{b}$} \\
\hline Mother & $6.31 \pm 2.02$ & $19.1 \pm 1.73$ & $20.9 \pm 2.30$ \\
\hline Father & $6.26 \pm 1.66$ & $19.4 \pm 1.37$ & $21.2 \pm 2.17$ \\
\hline $\mathrm{T}=$ Test; P-value & $\mathrm{T}=0.235 ; 0.428$ & $\mathrm{~T}=-1.660 ; 0.141$ & $\mathrm{~T}=-1.184 ; 0.284$ \\
\hline \multicolumn{4}{|c|}{ Nationality $^{\mathbf{b}}$} \\
\hline Saudi & $6.29 \pm 1.95$ & $19.2 \pm 1.66$ & $20.9 \pm 2.28$ \\
\hline Non-Saudi & $6.56 \pm 2.07$ & $19.0 \pm 2.00$ & $21.0 \pm 2.29$ \\
\hline $\mathrm{T}=$ Test; $\mathrm{P}$-value & $\mathrm{T}=-0.398 ; 0.875$ & $\mathrm{~T}=0.324 ; 0.985$ & $\mathrm{~T}=-0.035 ; 0.901$ \\
\hline
\end{tabular}




\section{Academic Journal of Pediatrics \& Neonatology}

\begin{tabular}{|c|c|c|c|}
\hline \multicolumn{4}{|c|}{ City $^{\mathrm{b}}$} \\
\hline Inside Alrass & $6.21 \pm 2.17$ & $19.2 \pm 1.77$ & $20.9 \pm 2.54$ \\
\hline Outside Alrass & $6.35 \pm 1.81$ & $19.2 \pm 1.60$ & $21.0 \pm 2.13$ \\
\hline $\mathrm{T}=$ Test; P-value & $\mathrm{T}=-0.702 ; 0.985$ & $\mathrm{~T}=0.230 ; 0.312$ & $\mathrm{~T}=-0.723 ; 0.914$ \\
\hline \multicolumn{4}{|c|}{ Residence place ${ }^{\text {b }}$} \\
\hline Urban & $6.29 \pm 1.95$ & $19.2 \pm 1.64$ & $20.9 \pm 2.28$ \\
\hline Rural & $6.33 \pm 1.89$ & $19.1 \pm 1.82$ & $21.2 \pm 2.28$ \\
\hline $\mathrm{T}=$ Test; P-value & $\mathrm{T}=-0.097 ; 1.000$ & $\mathrm{~T}=0.391 ; 0.941$ & $\mathrm{~T}=-0.838 ; 0.355$ \\
\hline \multicolumn{4}{|c|}{ Father educational level $^{\mathrm{b}}$} \\
\hline High school or below & $6.28 \pm 2.00$ & $19.1 \pm 1.82$ & $20.8 \pm 2.24$ \\
\hline Bachelor or higher & $6.31 \pm 1.92$ & $19.2 \pm 1.57$ & $21.1 \pm 2.29$ \\
\hline $\mathrm{T}=$ Test; P-value & $\mathrm{T}=-0.136 ; 0.949$ & $\mathrm{~T}=-1.007 ; 0.280$ & $\mathrm{~T}=-0.964 ; 0.264$ \\
\hline \multicolumn{4}{|c|}{ Mother educational level $^{\text {b }}$} \\
\hline High school or below & $6.09 \pm 1.84$ & $19.2 \pm 1.71$ & $20.8 \pm 2.28$ \\
\hline Bachelor or higher & $6.36 \pm 1.98$ & $19.2 \pm 1.65$ & $21.0 \pm 2.28$ \\
\hline $\mathrm{T}=$ Test; P-value & $\mathrm{T}=-1.223 ; 0.163$ & $\mathrm{~T}=0.376 ; 0.522$ & $\mathrm{~T}=-0.777 ; 0.389$ \\
\hline \multicolumn{4}{|c|}{ Working in medical field } \\
\hline Yes & $6.45 \pm 2.74$ & $19.3 \pm 1.45$ & $20.7 \pm 2.07$ \\
\hline No & $6.29 \pm 1.90$ & $19.2 \pm 1.67$ & $20.9 \pm 2.29$ \\
\hline $\mathrm{T}=$ Test; P-value & $\mathrm{T}=0.353 ; 0.427$ & $\mathrm{~T}=0.338 ; 0.996$ & $\mathrm{~T}=-0.450 ; 0.441$ \\
\hline \multicolumn{4}{|c|}{ Number of children ${ }^{a}$} \\
\hline One & $6.33 \pm 2.05$ & $19.1 \pm 1.54$ & $21.1 \pm 2.35$ \\
\hline Two to three & $5.89 \pm 2.16$ & $19.2 \pm 1.61$ & $20.8 \pm 2.34$ \\
\hline More than three & $6.48 \pm 1.79$ & $19.2 \pm 1.72$ & $21.0 \pm 2.24$ \\
\hline $\mathrm{F}=$ Test; P-value & $\mathrm{F}=3.619 ; 0.041^{* *}$ & $\mathrm{~F}=0.070 ; 0.608$ & $\mathrm{~F}=0.561 ; 0.531$ \\
\hline \multicolumn{4}{|c|}{ Having children under school age ${ }^{b}$} \\
\hline Yes & $5.98 \pm 2.17$ & $19.1 \pm 1.72$ & $20.7 \pm 2.31$ \\
\hline No & $6.55 \pm 1.70$ & $19.3 \pm 1.61$ & $21.2 \pm 2.24$ \\
\hline $\mathrm{T}=$ Test; P-value & $\mathrm{T}=-3.003 ; 0.016^{* *}$ & $\mathrm{~T}=-1.306 ; 0.263$ & $\mathrm{~T}=-1.913 ; 0.032^{* *}$ \\
\hline \multicolumn{4}{|c|}{ Child unable to complete vaccinations ${ }^{\text {b }}$} \\
\hline Yes & $5.89 \pm 2.43$ & $18.8 \pm 2.07$ & $20.4 \pm 2.41$ \\
\hline No & $6.48 \pm 1.67$ & $19.4 \pm 1.42$ & $21.2 \pm 2.17$ \\
\hline $\mathrm{T}=$ Test; P-value & $\mathrm{T}=-2.861 ; 0.004^{* *}$ & $\mathrm{~T}=-3.469 ; 0.007^{* *}$ & $\mathrm{~T}=-3.642 ;<0.001^{* *}$ \\
\hline
\end{tabular}

aP-value has been calculated using Kruskal Wallis test.

${ }^{\mathrm{b}} \mathrm{P}$-value has been calculated using Mann Whitney $\mathrm{U}$ test.

**Significant at $p<0.05$ level.

\section{Discussion}

The prevention toward many diseases started during childhood vaccination. Nevertheless, childhood immunization is an inadvertent method to evaluate child health care [7]. The present survey aimed to give further insights regarding the knowledge, attitude and practice of parents toward childhood vaccination. The overall knowledge score of parents toward childhood vaccination was $6.29 \pm 1.95$ out of 10 and moderate knowledge were found to two-third of the parents (66.9\%), followed by good knowledge (26.6\%) and poor knowledge (6.5\%). In Central Region [8], the total knowledge score of parents regarding childhood vaccination was slightly higher than our results with $8.08 \pm 1.8$ out of 11 while in a paper published by Habib et al, [9] it was determined that the overall Knowledge, Attitude and Practice (KAP) of parents toward childhood immunization was generally good among $87.2 \%$ of the parents which was also higher than our study findings. In neighboring country [10], the overall knowledge score of parents was $8.58 \pm 2.19$ with majority of the parents had moderate knowledge (63.3\%), followed by high knowledge $(23.3 \%)$ and low knowledge $(13.5 \%)$ which was in accordance with our study findings. However, in Nepal [11], a great proportion of the parents were found to have good knowledge $(72.5 \%)$ and this has been corroborated by the study published in India [12], where they reported $72.7 \%$ of the parents were having god knowledge, 
followed by average $(21.8 \%)$ and poor knowledge $(5.4 \%)$. These results showed better knowledge when compared to our study outcome. This study has shown that the attitude of parents toward childhood immunization was generally positive (82.7\%) while the rest were either having an average attitude $(16.1 \%)$ or negative attitude $(1.2 \%)$ with an overall mean attitude score of $19.2 \pm$ 1.67 out of 21 . This report is consistent from the paper published in India [12]. They reported good attitude toward childhood vaccination had been detected from $85.4 \%$ of the parents, while average and poor knowledge were detected from $11.8 \%$ and $2.7 \%$ respectively. In Georgia [13], most mothers (97\%) had positive attitude toward child immunization which was slightly higher than our study outcome. Additionally, a positive attitude toward childhood immunization were also reported in a study conducted by Bamatraf \& Jawass [10], which was congruent with our study result. The overall practice toward childhood immunization was generally good which was observed from $60.9 \%$ of the parents, followed by moderate practice $36.7 \%$ and few had poor practice $(2.4 \%)$ with a mean score of $20.9 \pm 2.28$ out of 24 points. To our knowledge this is the first paper in Saudi Arabia that calculated the overall mean practice score of the parents. On the other hand, a study published in Malaysia [14], reported that female participants had better practice than male participants (Female $48.3 \%$ vs Male $38.4 \%)$. It also important to note that nearly all parents (87.5\%) in this study indicated that their child completed the immunization programs. Various papers reported good adherence to childhood immunization [11-13]. In contrast, Vezzosi et al, [15] accounted that more than one third of parents had vaccinated their child (38.4\%) and almost two-third were actually encourage by their healthcare professionals to vaccinate their child which was not consistent with our study result.

Moreover, a positive but highly significant correlation had been detected between knowledge, attitude and practice score. Suggesting that, as the knowledge score increase the attitude and practice score will also increase. This finding is consistent from the paper published by Al-Zahrani [8]. He reported a moderate positive correlation had been observed between total knowledge score and total attitude score of child vaccination. This has been supported by Trushitkumar et al, [12] which they observed a very significant correlation was seen between the parental knowledge and attitude score. In this study, we also discovered that the knowledge of those parents with two to three children are significantly less compared to those with one child or more than three children. Furthermore, those with having children under school age are significantly less of having knowledge and practice toward the childhood immunization while those parents who were unable to complete childhood vaccination programs were also found to have less knowledge, attitude and practice toward childhood vaccination compared to those who were able to complete childhood vaccinations program. The factors associated with KAP varies with each region. For example, in Saudi Arabia, Al-Zahrani [8], reported that the factors significantly associated with better knowledge score and positive parental attitude regarding child vaccination were source of information about child vaccination from TV, internet and journals/newspapers, parents with first child, younger age, and higher level of education while Yousif et al, [16] indicated gender, residence and educational level were the factors significantly associated with both parents knowledge and attitude towards immunizations. In neighboring country [10], they accounted age group and the number of their pre-school children were statistically significant at the mean score of knowledge. In Nepal [11], many factors were attributed to the level of knowledge such as gender, ethnicity, education level, occupation, having radio, TV and mobile phone at home while ethnicity, occupation living condition and education were statistically significant for immunization practice. In Georgia [13], a significant association was found between mothers' education, practice and attitude regarding immunization.

\section{Conclusion}

There is a moderate knowledge among parents toward childhood immunization while the consensus toward attitude and practice deemed positive and good. Furthermore, unable to complete child vaccination was the significant predictor of knowledge, attitude and practice toward childhood vaccination. In this regard, an increase of knowledge toward childhood vaccination is needed in our region. Thus, it is necessary to raise community awareness on the importance of immunization by education programmes, internet and mass media.

\section{Conflict of Interest}

The author declares that there is no conflict of interest.

\section{Ethical Approval Statement}

The local IRB had approved this study, individual verbal consent was taken prior to participation.

\section{References}

1. Al-Zaharani J (2013) Knowledge, Attitude and Practice of Parents Towards Childhood Vaccination. Majmaah J Heal Sci 1(1): 23-32.

2. Yousif MA, Ahmed Abdulrahman Albarraq, Mustafa Awad A Abdallah, Abubaker Ibrahim Elbur (2014) Parents' Knowledge and Attitudes on Childhood Immunization, Taif, Saudi Arabia. J Vaccines Vaccin 5(1).

3. Alenazi AAS, Alshareef RA, Alabudib FA (2017) Assessment of Knowledge and Attitude and Practice of Parents about Immunization in Jeddah City, 2017. Egypt J Hosp Med 69(7): 2939-2943.

4. Alyami AR, Alhashan GM, Nasser IA (2018) Knowledge, Beliefs and Practices of Parents towards Childhood Vaccination in Najran City, Saudi Arabia. Egypt J Hosp Med 70(1): 1-7.

5. Favin M, Steinglass R, Fields R, Banerjee K, Sawhney M (2012) Why children are not vaccinated: a review of the grey literature. Int Health 4(4): 229-238.

6. Awadh AI, Hassali MA, Al-lela OQ, Bux SH, Elkalmi RM, et al. (2014) Immunization knowledge and practice among Malaysian parents: a questionnaire development and pilot-testing. BMC Public Health 14(1): 1107.

7. Tang CW, Huang SH, Weng KP, Ger LP, Hsieh KS (2011) Parents' Views About the Vaccination Program in Taiwan. Pediatrics and Neonatology 52: 98-102. 
8. Al-Zahrani J (2013) Knowledge, attitude and practice of parents towards childhood vaccination. Majmaah Journal of Health Sciences 216(1216): 1-20.

9. Saleh A, Alrashidi AA, Bukhari MA, Habib RF, Alsubhi RA, et al. (2018) Assessment of knowledge, attitude and practice of parents towards immunization of children in Saudi Arabia, 2018. The Egyptian Journal of Hospital Medicine 71(2): 2585-2589.

10. Bamatraf FF, Jawass MA (2018) Knowledge and Attitude Towards Childhood Immunization among Parents in Al-Mukalla, Yemen. Middle East Journal of Family Medicine 7(10): 24.

11. Devkota S, Simkhada P, van Teijlingen E, Rai LD (2013) Parents Knowledge and Practices to Childhood Immunisation in Nepal: Implications for Health Policy. Health Science Journal 7(4): 370.

12. Trushitkumar BP, Pathak R, Singh R, Alves V, Mahesh NM, et al. (2017) Assessment of Parents' Knowledge, Attitude and Practice about Child
Vaccination in Rural areas. Journal of Pharmaceutical Research 16(3): 229-236.

13. Verulava T, Jaiani M, Lordkipanidze A, Jorbenadze R, Dangadze B (2019) Mothers' knowledge and attitudes towards child immunization in Georgia. The Open Public Health Journal 12(1).

14. Aziz SO, Ahmad ZU, Ghadzi SM, Abbasi YF, Sivadasan S, et al. Knowledge and practice towards vaccination: a cross-sectional study among the parents in Sungai Petani, Kedah, Malaysia. Int J Sci Eng Res 9(8): 17111717.

15. Vezzosi L, Santagati G, Angelillo IF (2017) Knowledge, attitudes, and behaviors of parents towards varicella and its vaccination. BMC infectious diseases 17(1): 172.

16. Yousif MA, Albarraq AA, Abdallah MA, Elbur AI (2013) Parents' knowledge and attitudes on childhood immunization, taif, saudi arabia. J Vaccines Vaccin 5: 215.

\section{Your next submission with Juniper Publishers will reach you the below assets}

- Quality Editorial service

- Swift Peer Review

- Reprints availability

- E-prints Service

- Manuscript Podcast for convenient understanding

- Global attainment for your research

- Manuscript accessibility in different formats

( Pdf, E-pub, Full Text, Audio)

- Unceasing customer service

Track the below URL for one-step submission

https://juniperpublishers.com/online-submission.php 